\title{
Urgences
}

\section{Les jeux sont faits}

\section{Robert Petit}

Numéro 20, mai 1988

Appellation contrôlée

URI : https://id.erudit.org/iderudit/025474ar

DOI : https://doi.org/10.7202/025474ar

Aller au sommaire du numéro

Éditeur(s)

Urgences

ISSN

0226-9554 (imprimé)

1927-3924 (numérique)

Découvrir la revue

Citer ce document

Petit, R. (1988). Les jeux sont faits. Urgences, (20), 30-30.

https://doi.org/10.7202/025474ar

Ce document est protégé par la loi sur le droit d'auteur. L'utilisation des services d'Érudit (y compris la reproduction) est assujettie à sa politique d'utilisation que vous pouvez consulter en ligne.

https://apropos.erudit.org/fr/usagers/politique-dutilisation/
Cet article est diffusé et préservé par Érudit.

Érudit est un consortium interuniversitaire sans but lucratif composé de l'Université de Montréal, l'Université Laval et l'Université du Québec à Montréal. Il a pour mission la promotion et la valorisation de la recherche. https://www.erudit.org/fr/ 


\section{ROBERT PETIT \\ Les jeux sont faits}

Celui-là je présume que c'est l'organisateur, tiré à quatre épingles, la componction tout usage, cocktails, allocutions, baisemains, conférences, concerts, patinage artistique, il aura voulu profiter de ce que les Jeux attirent l'attention pour nous réunir. Il se promème parmi nous, fait s'il vous plaît (bis) sans vraiment le dire, nous nous engouffrons dans l'amphithéâtre comme dans l'antre du plaisir. Mon voisin, particulièrement, semble $€$ n attendre un spectacle féérique, on dirait un gyrophare, debout, asisis, la bouche ouverte, la dentition éparse, le sourire aéré, il connaît tout le monde, bonjour à gauche et à droite, une grande perche le lui rend bien, baiser mouillé (ter), seulement elle m'écrase les pieds. Ce! colloque, je m'en serais volontiers exempté, je ne me fais pas d'illusion sur ce qui motive ma présence ici à deux semaines d'avis, un désistement de dernière minute, je me sens dans la peau d'un skieur somalien.

Je passe tout de suite aprës une pimbêche dont je renonce à comprendre le titre de l'exposé non plus que tout ce qui fera le ravissement de mon voisin penclant la prochaine demi-heure. Vivre en Amérique sans parler l'anglais, je suis moi-même pas mal dans mon genre, j'ai une excuse, mes grands-parents conversaient in English quand ils me gardaient, enfant, je les détestais pour un tas d'autres raisons, j'aurais voulu au moins qu'ils me disent comment on traduit mon prénom, rien à faire, pas d'équivalent, comment aurais-je pu trouver de l'intérêt aux langues étrangères? J'ajoute à ma défense qu'il faut des dispositions peu banales pour suivre la conférencière: chaque mot lui demande l'effort labial des fumeurs de cigarettes sans filtre quand ils cherchent à cracher des brins de tabac.

Elle finit par Fank you, nous applaudissons, c'est-à-dire que nous tapotons sur les tables. Puis rien.

Vient enfin à quelqu'un l'idée de consulter le programme. On se rend compte du retrait du distingué collègue, l'organisateur se souvient de moi, il m'appelle, ne parvient pas à prononcer mon nom. Personne ici, pas même lui, ne me connaît, ce qui me dispense de leur faire la conversation, dans une langue qu'ils ne comprendront pas, sur un sujet qu'au fond je n'ai jamais pigé. Je tapoche sur la table, je me lève avec fracas, en quelques onomatopées je manifeste mon déplajsir devant pareille organisatior de broche à foin, je sens qu'on acquiesce, je sors. 